\title{
COMMITTEE OF ASTIN
}

$\begin{array}{ll}\text { Chairman } & \text { AMMETER Hans, Zurich } \\ \text { Vice Chairman } & \text { MASTERSON Norton E., Stevens Point } \\ \text { Treasurer } & \text { THYRION Paul, Brussels } \\ \text { Members } & \text { JOHANSEN Paul, Copenhagen } \\ & \text { OTTAVIANI Guiseppe, Rome } \\ & \text { SOUSSELIER Jean, Paris } \\ & \text { STERNBERG Ingvar, Malmö } \\ & \text { WELTEN C. P., Amsterdam } \\ & \text { BEARD Robert Eric, } \\ \text { Secretary } & \text { PEARL Assurance Company Ltd., } \\ & \text { 252, High Holborn, } \\ & \text { London W.C. I }\end{array}$

Honorary Chairman FRANCKX Edouard, Brussels

Past Chairman
I957-I960 JOHANSEN Paul, Copenhagen
rg6o-rg62 Henry Marcel, Paris
I962-I964 BEARD Robert Eric, London

The Committee is not responsible for statements made or opinions expressed in the articles, criticisms and discussions published in this Bulletin.

Le Comité rapelle que seul l'auteur de chaque publication est responsable des fajts qu'il expose et des opinions qu'il exprime. 